\title{
Using Chunking Technique To Improve English Reading Comprehension For First-Year English Majors At Thai Nguyen University Of Education
}

\author{
Pham Thi Kieu Oanh*, Dang Thi Thanh Dung**, Ngo Thi Ngoc Anh ${ }^{* *}$ \\ * Foreign languages education faculty, Thai Nguyen University of Education \\ DOI: 10.29322/IJSRP.11.08.2021.p11660 \\ http://dx.doi.org/10.29322/IJSRP.11.08.2021.p11660
}

\begin{abstract}
Reading comprehension is incredibly complex to students who use English as a second language because it requires them to interpret not only the main meaning of the text but also the intention of the writer. The English learners always have to struggle to use different reading techniques to grasp the meaning of the passage. One of the most effective techniques which can help students enhance reading comprehension in English is "Chunking technique". This study aims to investigate a) the current situation of the first-year English majors' reading comprehension at Thai Nguyen University of Education; b) the effectiveness of using Chunking technique in order to improve English reading comprehension for first-year English students. The researchers used questionnaires and experiments as two main instruments to collect data, and SPSS 20 (Statistical Package for the Social Sciences 20) was used to analyze the data. In the process of research, 20 students divided into control group and experimental group took part in the experiment within 8 weeks. The findings of this study showed that Chunking technique had a positive impact on students' reading comprehension when the mean score of students' post-tests of experimental group (6.05) was higher than that of the controlled group (5.32). It is also proved that this research was reliable to implement. The researchers clarified the effectiveness of using Chunking technique so that not only teachers but also students can achieve their goals concerning reading comprehension development.
\end{abstract}

Index Terms- Chunking technique, experiment, reading comprehension.

\section{INTRODUCTION}

$I^{t}$ is not surprising if English becomes the most commonly spoken language in the world. In Vietnam, English is considered as a second language and a compulsory subject which is taught in a large scale from primary up to university level of education. With the rapid growth and expansion of English in Vietnam, both teachers and students have to use English as a means of communication at a certain level of proficiency in four skills: listening, speaking, reading and writing.

Learners need to master four English skills, in which reading skills should be given more attention in the classroom. Rivers (1981) claimed that reading was considered as the most significant activity in class because it helps students not only enrich their language and vocabulary, but also develop creativity. Hung \& Tzeng (2007) argued that reading is the quickly and modestly way to expand people's level in education. Reading is a modality to discover the world; by reading, people can learn a great deal of different topics and widen their perspectives. Moreover, reading skill should not be separated from other skills. This means that people talk or write based on all things that they have read. For instance, in speaking, learners could talk about diverse topics and fields because they have had significantly information through reading texts. Reading, in a nutshell, is the most significant of the four language skills since it can assist English learners in improving their total language ability (Brown \& Krashen, 2007). In English reading, especially academic reading, students are required to comprehend the text adequately. Therefore, English learners always express their anxiety and frustration in reading comprehension. That is the reason why reading techniques could be employed in improving reading comprehension.

In Thai Nguyen University of Education, English is not really concerned with all students although they have to achieve at least B1 certificate to be able to graduate. Students frequently read all the words, phrases, sentences, and paragraphs in order to get the meaning of the texts as a whole. Nonetheless, they have not entirely understood what they are reading in syllabus and the curriculum, and they do not know how to comprehend the texts. In other aspect, the students are not into reading text because they thought that reading an English text is uninteresting. Reading comprehension can't be too difficult with junior or senior students, but it is the main obstacle with the first-year students in improving reading English. Especially, the first-year English majors have to struggle with learning English because they have just enrolled to the university. Moreover, the curriculum in university is different from the curriculum at high school. The students have problems in comprehending the text and getting the main ideas of the text. A lot of students make mistake in English reading comprehension since they difficultly catch information from the text and answer questions based on the text. Currently, lots of teaching methods and techniques are offered to promote students in developing their ability in reading and one of these techniques is "Chunking technique". "Chunking technique" is an effective technique which can help gather group of words into short important expressions (for the most part three to five words). According to Miller, G. (1956) in chunking, the readers taught with chunking scored better than those who were taught without chunking. When information 
is chunked into groups, it is simpler to recall the information by remembering the groups rather than each individual bit of information. In addition, students can perceive the reading comprehension through using Chunking technique because it helps students practice the ability to comprehend challenging texts in reading English.

Almost English learners usually learn reading by using skimming and scanning but not "Chunking", so this technique is quite unpopular to them. Furthermore, there is a great deal of information related to "Chunking technique", but it is really hard to find several relevant researches about this technique. Based on the background of subjects in this research and the novelty of "Chunking technique", the researchers are encouraged to conduct the study titled "Using Chunking technique to improve English reading comprehension for first- year English majors at Thai Nguyen University of Education”.

\section{LITERATURE REVIEW}

\section{Definitions of reading comprehension}

A number of different research studies have been carried out by researchers, to account for the definition of reading comprehension. Most researchers believe that reading comprehension is not simply recognizing individual words, or even understanding each individual word as readers' eyes pass over it. Ommagio $(2006: 14)$ refers to comprehension that is the process of understanding meaning from the given text which involves word knowledge, reasoning and thinking. Readers can efficiently proceed from the stage of learning to read to the ultimate objective of reading to learn as their comprehension matured greatly (Alonzo, Duesbery, Tindal \& Yovanoff, 2005). In the simple term, Harris \& Hodges (1995:98) defined that reading comprehension is the understanding of a printed passage's structure through an exchange of ideas between the reader and the written text. Lipson \& Wixson (2003: 23) stated that reading comprehension is the ability to apply previously knowledge to construct meaning for a given text. It could be understood that reading comprehension is the process of understanding written texts. The readers are expected to elicit information by using comprehension skills. In addition, Graham (2007:8) indicated that reading comprehension covers much more than readers' responses to a text. Reading comprehension is a multi-constituent, highly complicated process that comprises many interactions between readers and what they present to the text as well as variables related to the text itself. Seyed (2010:376-80) referred comprehension involved in the ability to understand the ideas provided in the complete text by going beyond the words. Alternatively, Snow (2002:11) considered reading comprehension as the process of altogether to excerpt and construct meaning through collaboration and interference with a written language.

\section{The purposes of reading comprehension}

Many researchers have referred to the reason why we read. Readers can efficiently proceed from the stage of learning to read the ultimate objective of reading as their comprehension skills improve (Alonzo, Duesbery, Tindal \& Yovanoff 2005).

Wallace (1992:6-7) described the main objectives of reading as follows:
Reading for survival: People have discovered that reading is quite beneficial or significant in their daily lives, such as when reading an instruction sign. Reading for survival satisfies immediate requirements.

Reading for learning: Reading is an important activity at school because it is prepared to support learning. Students must translate their material literally or metaphorically while reading in order to learn vocabulary, identify relevant groupings or structure, use a printed text as a model for writing, and practice pronunciation.

Reading for pleasure: Reading for enjoyment is a way of achieving happiness. Some readers are drawn to the text because of its sound, rhyme, or rhythm. The literature that was read was written with the intention of providing delight, as seen by reading narrative texts. To increase students' motivation for English reading, it should be assessed as a motivated activity in which students are well-informed about what they should perform.

\section{Types of reading comprehension}

Based on the reading comprehension levels, there are five types of reading comprehension which were defined through the experiences in teaching, reading and analyzing materials. Pearson \& Johnson (1978) also supported for this taxonomy.

\section{Literal comprehension}

Literal comprehension focuses on the main idea of the text. It means that literal comprehension is the ability to comprehend the basic meaning of the text, such as concepts, dates, times, and places mentioned in the reading passages. Students can find the information which is shown directly in the text to answer the basic questions related to who, what, when, where and why. Students can employ literal comprehension skills such as underlining keywords, skim reading and scanning to gather the information efficiently.

\section{Reorganizational comprehension}

Reorganizational comprehension is the next type. Students must take information from multiple areas of the text and integrate them to answer the relevant questions. For example, in a reading lesson, the students learnt that a man named Joey was born in 1942 at the beginning of the text and died in 2010 at the end of the text. After reading whole text, students need to organize the information to answer the question like "How old was Joey when he died?" The student must put two pieces of information from different portions of the book together.

\section{Inferential comprehension}

Making inferences is more necessary than a literal comprehension. Students will have difficulty to comprehend the text because the information in the text is not explicitly stated. To answer the comprehension questions related to this type, students have to combine their literal grasp of the text with their own knowledge and intuitions to make an inference. Readers are required to answer the comprehension questions based on their own knowledge of the topic and the information given in the text. Evaluation comprehension

Students need to make judgment about some aspect of the text while reading English, and they must know how to relate their real -life experience to existing knowledge or opinion. It means that this type of comprehension uses the information collected from the text to form new ideas. This allows students to connect 
their own experiences to the literature and judge the text's quality, values, and generalizations.

\section{Affective comprehension}

Affective comprehension refers to how a plot of the story works, how the characters fit into the story, and readers' emotion towards the story. The students need to understand the social and emotional aspects hidden in each text. It means this type of comprehension requires students to grasp the underlying meaning of a story. The learners can also express their own feeling about the reading passage, and this also helps students develop their critical thinking in English reading.

\section{Definitions of "Chunking technique"}

In order to improve reading comprehension, "Chunking technique" was defined, and employed in different experiments by researchers. Chunking is a technique to divide sentences into short relevant phrases including three to five words (Casteel, 1988). Another outstanding finding can be seen in the research of Franks \& Valentine (1979:48) that Chunking is used as a process of organizing or clustering information into compact thought units, such as phrases or clauses. Moreover, Tanaka (2006) also pointed out that Chunks are not units with complete, self-contained meaning. Especially, chunks form logical chains of meaning in reading comprehension, assisting learners in grasping the meaning of the entire sentence. According to Malamed (2012), Chunking means that the reading passage is broken down into smaller pieces, so the brain can absorb and process the information easily. Furthermore, Smith (1982) regarded chunking as a useful way to help the information placed in short-term memory. Likewise, the APA Dictionary of Psychology defined chunking as the process converting the large pieces of information into smaller units called chunks that are easier to recall in short-term memory.

\section{The procedure of chunking technique in reading comprehension}

According to Malamed (2012), there are five stages in the procedure of chunking technique to apply in reading comprehension:

1) Prepare: A multi-page reading can be divided into sections or paragraphs. Students should fill out a graphic organizer with information on each "chunk."

2) Review reading strategies: Students find and look up the new words, make a list of synonyms, then underline noteworthy places and persons, finally read aloud and multiple times.

3) Chunk the text: Teachers will chunk the passages for students in advance if this is the first time they have employed this technique. Students can work in pairs or alone on chunking texts. The length of chunks might vary depending on the students' reading abilities.

4) Paraphrase meaning: Students should use their own words to rewrite "chunks" based on their perception through context of the paragraph.

5) Assess and share: Teacher can use the rewritten text to assess students' understanding of reading lesson and reading ability. Students also can discuss to compare their versions of the text with their classmates.

\section{Advantages and Disadvantages of Chunking technique}

Chunking technique is one of the best techniques in several fields related to learning a foreign language. Chunk reading is important and essential for helping readers comprehend how meaning in English is produced in order to open the door to reading comprehension. Because chunking is one of the component impacts on reading fluency, learners will be able to read in chunks rather than word by word (Tanaka, 2006). Moreover, Casteel (1989) formulated that some readers, particularly those who are classed as poor or low ability readers, benefit from the presentation of chunked material separated into meaningful involved groupings of words. Daniel Bor (2012), stated that chunking is a metaphor for our ability to "hack" the limits of our memory. It means textual information may be recalled more easily, and sentence meanings can be grasped more quickly. The brain does not cope with words one by one in most circumstances; however, it can handle a small group of three to five words (chunk). Reading speed will improve as a result of this strategy, and reading skills will become more natural and "absorbent."

Despite the fact that many research papers on chunking have been published, many students still do not understand how to use it when reading English. Defect, deficiency, disruption, and difference are four distinct "assumptions" or explanations proposed to explain for reading difficulties, Wiener and Cromer (1967). According to Rasinski (1989), when students make a frequent error, it is hard to notice where a phrase begins and finishes. Rasinski also reports that beginners and those attempting to grasp complex materials are more likely to make chunking mistakes. The students are unable to comprehend the meaning of the words and phrases used to split the material into pieces.

\section{Previous studies}

Nowadays, there are numerous studies on the term "chunking technique" which have been undertaken around the world. In addition, Chunking strategy has been studied extensively to help students to improve their reading comprehension.

In 2015, Rinii Anggraeni investigated on "The Effectiveness of Using Chunking Strategy to Improve Students' Reading Comprehension at the second-year of SMP Negeri 2 Barombong". The major goal of this study was to see if chunking approach is helpful in improving second-year SMP Negeri 2 Barombong students' reading comprehension and to find the students' attitude toward learning by utilizing chunking technique. The results of this study revealed that chunking method has been successful in improving students' reading comprehension, with the experimental group's mean post-test score of 56. It was higher than the control group, which had a total of only 23 people.

Ausama (2018) carried out a study named "Investigating Iraqi EFL College Students' Awareness and Use of Lexical Chunks". The purpose of the study was to find out the awareness and usage of lexical chunks among Iraqi EFL students. The following conclusions have been reached as a result of the data analysis:

1. The awareness of lexical chunks among third-year EFL College students was medium

2. Third-year EFL College students used lexical chunks in an inappropriate amount and had trouble in creating them 
3. There was a statistically significant difference between Iraqi EFL college students' awareness and use of lexical chunks in favor of awareness

Che Lah, N. \& Mohd Saat, R. (2015) explored using chunking methods in Short Term Memory (STM) for upper secondary pupils to improve mixed chemical learning skills. Students used a variety of chunking methods, but three patterns stood out at the STM level: similar chunking, mixed chunking, and characteristic chunking. Therefore, as can be seen that "Chunking technique" was used in different fields.

Furukawa, J. M. (1978) compared results of students with high and low cognitive processing capacities. It was found that chunking method had a significant impact on the cognitive capacities. The retention following learning with the chunking' method may be perfect.

Graham, D. B. \& William G. P. (2006) proposed an innovative, blended teaching method including Chunking technique. Our memories are not only structured and kept in chunks, but they are also reinforced via repeated exposure to a concept, idea, or ability. In the sense that chunks are formed as bits of information and compressed or merged into a chunk, and chunking provides an outlet for recurrence.

Miller, G. (1956) indicated that chunking refers to Chunking refers to the act of arranging and combining tiny bits of information into bigger clusters. The capacity to chunk information (a) aids in remembering more, (b) provides a way of retrieving the information that is eventually stored in one's memory, and (c) improves the quantity of information we can deal with. This process, according to Miller, is ongoing process because we constantly recode information in order to integrate new information into our existing knowledge.

In Vietnam, there are a few research papers about chunking technique in improving reading comprehension. There are several articles refer to chunking technique as an excellent technique that help people not only in reading English but also in different fields in their life.

Mai Huong (2020) indicated in an article named "Using Chunking technique in IELTS Reading for beginners". The application process of "Chunking technique" in reading was introduced and used as an effective technique to improve reading comprehension.

Thoa Vu - an author of a website named 365Timviec (2020) proved the benefits of using chunking technique in reading comprehension.

\section{RESEARCH Methodology}

In this study, experimental research was employed as a research method. In collecting data, the researchers used two main instruments including questionnaires and tests in order to answer the research questions. The study included 20 first-year English majors at Thai Nguyen University of Education.

\section{Instruments for collecting data}

Creswell (2005) assumed that a questionnaire is a list of questions used in a survey of the research to collect the data which require the participants to fill out and return to the researchers. The participants choose answers to questions and supplies basic personal or demographic information. In this study, the researchers used the questionnaire firstly, for it can influence a large number of people in a very short time. The questionnaires focused on investigating the current situation in reading comprehension of first-year English majors K55. Test is one of the most effective tools of data collection. There were two tests that were carried out, namely, pre-test and post-test. They were designed to suit students' abilities. The pre-test was taken place at the beginning of the research. It helped measure students' level in both experimental group and control group. At the end of the projects, the post-test was carried out to know the result of the research after giving treatment.

\section{Participants}

The researchers worked with 20 English major K55 students from Thai Nguyen University of Education. Most of them are at the age of 18-19. One group was assigned to the experiment, while the other was assigned to the control. Experimental group (10 participants) was taught how to effectively use chunking technique in reading. The control group (10 participants) was given no treatment. These 20 selected students also have the basis English knowledge. They have enough English vocabulary to be able to participant in this study. Furthermore, most of them are freshmen, so they have to struggle with new environment. They have to deal with the challenge text in reading skills. The researchers helped students know the new method to learn English and know how to apply it in English reading comprehension.

\section{Findings \& Discussion Results from Questionnaires}




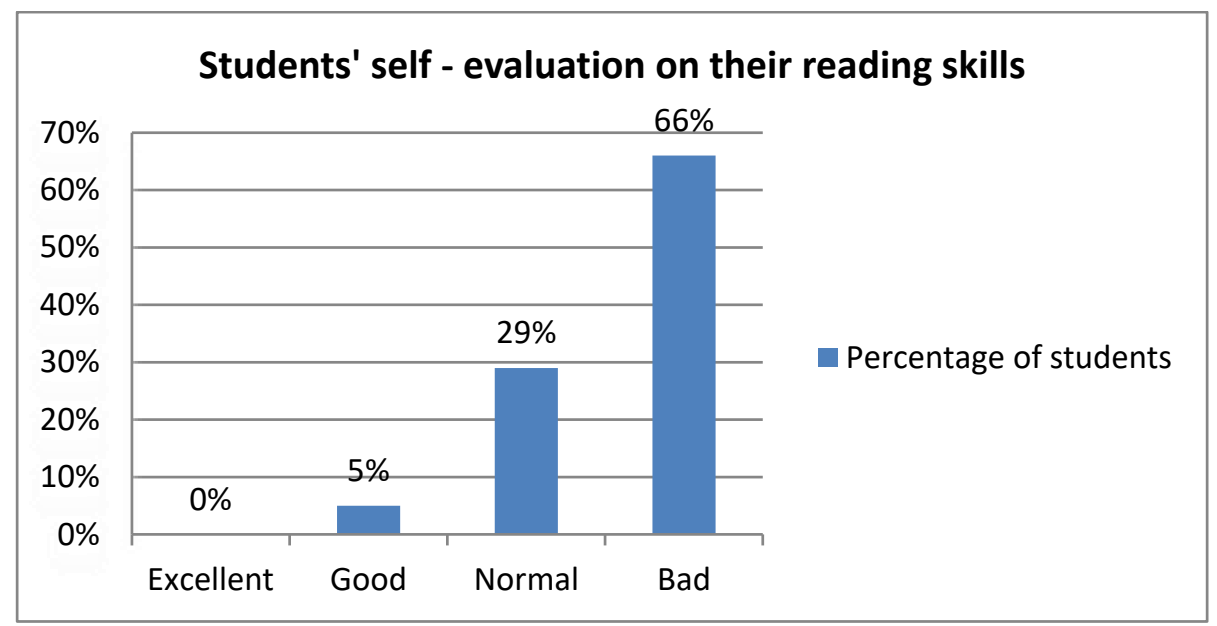

Chart 1. Students' self - evaluation on their reading skills

The bar chart above illustrates the proportion of students who assessed their competence in reading English. As can be seen from the figure, $66 \%$ of students thought that their English reading skills were bad, while just $5 \%$ of students thought that they were good at English reading comprehension. Meanwhile, there were $29 \%$ of students believed that their English reading competence were normal. No one chose the option "excellent". This fact can be understood that all of participants are freshmen, and almost students just have the basis English knowledge including vocabulary and grammar. The demonstration reveals that the students aware of their abilities in reading English, and it is obvious from the chart that they need more practice and training to improve their reading comprehension.

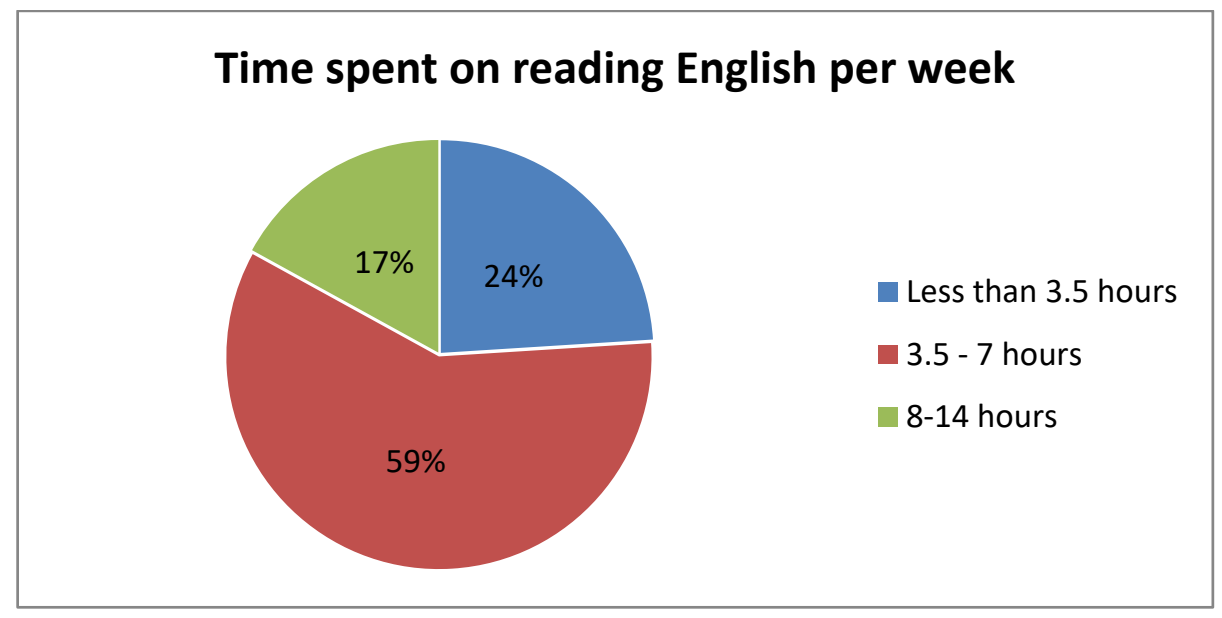

Chart 2. Students' spending on reading English per week

The pie chart 2 shows the percentage of weekly hours of students in reading English. As shown in the chart, the number of participants who chose the option "8-14 hours" was the least $(17 \%)$, while over a half of students $(59 \%)$ admitted that they spent from 3.5 to 7 hours on reading English in a week. 24\% of students thought that they read English less than 3.5 hours per week. This result indicates that all the students have spent their time reading English to improve their reading comprehension, but the time spent on reading is not enough to master English reading. Furthermore, the students need to spend more time at home reading English instead of reading at school only. 




\section{Chart 3. Students' habits of reading English}

Chart 3 shows four different things which students regularly do while reading. The largest number of students (39\%) agreed that the most frequent thing that they do in reading English is trying to understand all the words in the text. There were a lower percentage of students $(24 \%)$ who need to spend more time on reading while reading in English. Nine students (22\%) often only read topic sentence, including sentence and key words when they read English passages. 15\% of students used to feel tired and unfocused when they read long texts. The results showed that the participants also aware about the ways they use to read in English and how much they have to struggle with the challenging texts.

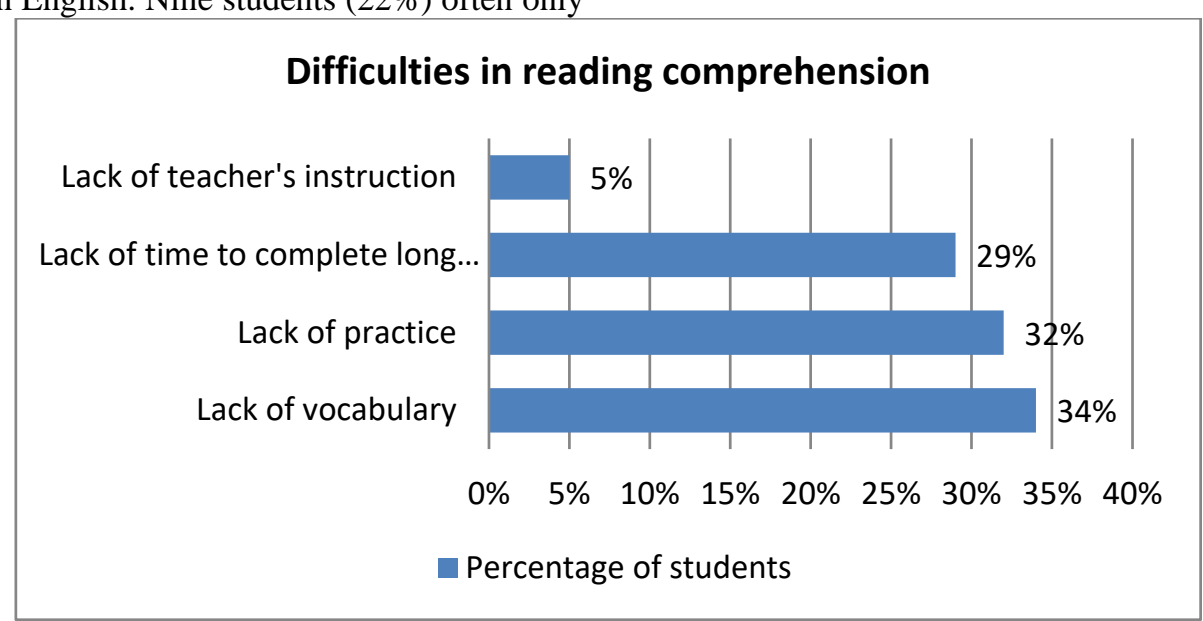

Chart 4. Students' difficulties in reading comprehension

Chart 4 depicts the difficulties which students have to face up with in reading. Overall, almost students perceived that they have difficulties in reading English because of five main reasons. The largest number of students (34\%) agreed that the biggest difficulty that they had in reading comprehension was lack of vocabulary. Although unknown words can be predicted while reading comprehension, students cannot understand a text or writer's intention without knowing what most of the words mean. The second difficult thing that the participants had while reading in English was lack of practice, as the figure for this option was $32 \%$. The students may not spend time on reading English in their daily life, so they can be unfamiliar with the challenging texts. $29 \%$ of the students found it hard to complete the long reading passages in a certain time. Only 5\% of the surveyed students claimed that they had difficulties in reading on account of lack their teachers' instruction. In addition, none of students applied that there were other obstacles. 


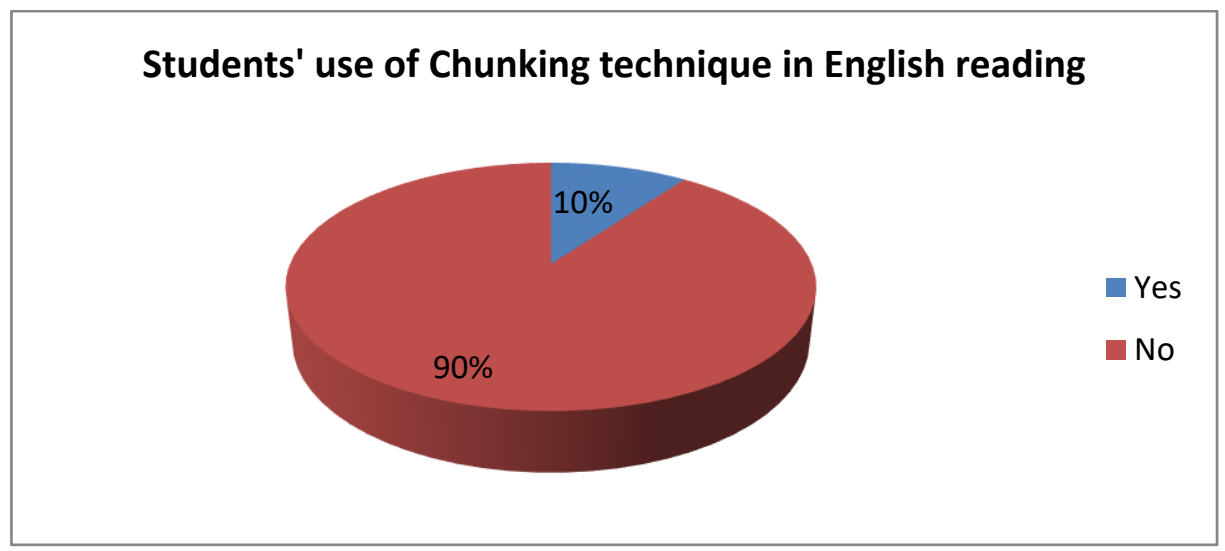

Chart 5. Students' use of "Chunking technique" in English reading

Chart 5 shows the novelty of the chunking technique towards the students by asking them whether this is the first time they experience chunking technique. There were $90 \%$ of students replied that this is their first-time knowing chunking technique, and $10 \%$ of them have known a little bit about this technique before.

\section{Results from Tests}

\begin{tabular}{|l|l|l|l|l|l|l|}
\hline No & Classification & \multirow{2}{*}{ Score } & Experimental Group & \multicolumn{2}{l|}{ Control group } \\
\cline { 4 - 7 } & & & F & P(\%) & F & P (\%) \\
\hline 1 & Excellent & 9.5 to 10 & 0 & $0 \%$ & 0 & $0 \%$ \\
\hline 2 & Very Good & 8.5 to 9.4 & 0 & $0 \%$ & 0 & $0 \%$ \\
\hline 3 & Good & 7.5 to 8.4 & 0 & $0 \%$ & 0 & $0 \%$ \\
\hline 4 & Fairly Good & 6.5 to 7.4 & 3 & $30 \%$ & 1 & $10 \%$ \\
\hline 5 & Fair & 5.5 to 6.4 & 2 & $20 \%$ & 4 & $40 \%$ \\
\hline 6 & Poor & 4.5 to 5.4 & 3 & $30 \%$ & 3 & $30 \%$ \\
\hline 7 & Very poor & 0 to 4.4 & 2 & $20 \%$ & 2 & $20 \%$ \\
\hline & Total & & 10 & $100 \%$ & 10 & $100 \%$ \\
\hline
\end{tabular}

\section{Table 1 . The classification of students' pre-test}

Table 1 shows the students' score of pre-tests both of experimental and control group. As can be seen on this table, no one in experimental group was good in reading comprehension, and it was similar with control group. In experimental group, 30\% of students had the score from 6.5 to 7.4 , and was accessed at fairly good level. By contrast, just 10\% students of control group got that level. Two students (20\%) were classified at fair level in experimental group, and the percentage of students' score at this level in control group was double. Furthermore, both experimental and control group had three students who were poor in reading English. Similarly, four students were very poor in reading in two groups. The data proved that the students' reading comprehension was still limited. Moreover, the students' reading competence in the control group employed in their pre-tests was the same as that in the experimental group.

\begin{tabular}{|l|l|l|l|l|l|l|}
\hline No & Classification & \multirow{2}{*}{ Score } & Experimental Group & \multicolumn{2}{l|}{ Control group } \\
\cline { 4 - 7 } & & & F & P(\%) & F & P(\%) \\
\hline 1 & Excellent & 9.5 to 10 & 0 & $0 \%$ & 0 & $0 \%$ \\
\hline 2 & Very Good & 8.5 to 9.4 & 0 & $0 \%$ & 0 & $0 \%$ \\
\hline 3 & Good & 7.5 to 8.4 & 2 & $20 \%$ & 0 & $0 \%$ \\
\hline 4 & Fairly Good & 6.5 to 7.4 & 2 & $20 \%$ & 2 & $20 \%$ \\
\hline 5 & Fair & 5.5 to 6.4 & 3 & $30 \%$ & 2 & $20 \%$ \\
\hline 6 & Poor & 4.5 to 5.4 & 1 & $10 \%$ & 3 & $30 \%$ \\
\hline 7 & Very poor & 0 to 4.4 & 2 & $20 \%$ & 3 & $30 \%$ \\
\hline & Total & & 10 & $100 \%$ & 10 & $100 \%$ \\
\hline
\end{tabular}

Table 2. The classification of students' post-test 
Table 2 illustrates the students' post-test score both of experimental and control group. It is clear that, in experimental group 2 (20\%) students were good, so there was a significant increase compared to pre-test which had no student getting this score whereas $0 \%$ of student in control group got the good score. The number of students who got poor and very poor scores fell considerably in experimental group. In experimental group, 3 $(30 \%)$ students were poor and very poor while in control group, it was $60 \%$. The increase in the number of the students in the top scores and the decrease in the number of the students in the lowest scores proved that the participants who were taught chunking technique have improved their English reading comprehension. Moreover, the students who were taught without using chunking technique have not improved too much because they didn't change their score scales.



Chart 6. The difference of mean score between experimental group and control group

Chart 6 represents the difference of mean score between experimental group and control group. In experimental group, the average score of pre-tests was 5.34, and the average score of posttest was 6.05. There was a significant increase in mean of experimental group about 0.71 . However, the difference in the average score between pre-test and post-test in control group was not too much, merely 0.12 (from 5.2 to 5.32 ).

\section{CONCLUSION}

In general, through the process of the research, there were some conclusions about the use of chunking technique to enhance English reading skills, identified by 20 students from the first-year English majors at Thai Nguyen University of Education. The information collected by questionnaires, pre-test, post-test and practice tests with the data analysis to answer the two research questions. Firstly, the students' questionnaire responses reveal a fact that the students have to cope with many difficulties in reading comprehension. Therefore, the new method stimulates students' interest and desire to learn reading comprehension. Secondly, there was a big difference between pre-test score and post-test score of the participants in the experimental group. Meanwhile, it was an unremarkable gap between pre-test score and post-test score of students in the control group. This illustrates that the participants' reading comprehension competence was improved when learning by chunking strategy. Hopefully, the Chunking technique will become an effective technique for both teachers and students to teach and learn reading comprehension.

\section{REFERENCES}

[1] Alonzo, J., Duesbery, L., Tindal, G. \& Yovanoff, P. (2005). Grade-level invariance of a theoretical causal structure predicting reading comprehension with vocabulary and oral reading fluency. Educational Measurement: Issues and Practice, 24(3), 4-12.
[2] Ausama (2018). Investigating Iraqi EFL College Students' Awareness and Use of Lexical Chunks. Academic Publishing ISBN: 978-6 0-0-28063.

[3] Brown, L. C. \& Krashen, S. (2007). What is Academic Language Proficiency? Singapore Tertiary English Teachers Society (STETS).

[4] Brown, H. Douglas. (2001). Teaching by Principles: An Interactive Approach to Language Pedagogy. Upper Saddle River, Prentice Hall Regents.

[5] Broughton, iG. iE. it. iAl. (2003). iTeaching iEnglish ias ia iforeigner ilanguage. London: iRoutledge iEducation, ilnc.

[6] Che Lah, N., Hassan, R. \& Mohd Saat, R. (2015). How Chunking and Learning get together. The Malaysian Online Journal of Educational Science.

[7] Creswell, J. W. (2005). Research design: Qualitative, quantitative, and mixed methods approaches (3rd ed.). Los Angeles: Sage.

[8] Casteel, C. (1988). Effects of chunked reading among learning disabled students: An experimental comparison of computer and traditional chunked passages.

[9] Casteel, C. (1989). Effects of chunked text-material on reading comprehension of high and low ability readers.

[10] Danied Bor (2012). The Ravenous Brain. Basic Books, 2012.

[11] Furukawa, J. M. (1978). Chunking Method of Teaching and Studying: Paper presented at the Annual Meeting of the American Psychological Association (Toronto, Canada, August 1978)

[12] Franks, R. \& Valentine, E. P. (1979). To Teach a Social Studies ConceptChunk It. Reading Horizons, 20(1) 47-54.

[13] Graham, iSteve. i(2007). iTeaching ireading icomprehension ito istudents iwith ilearning idifficulties. iNew iYork: iThe iGuilford iPress.

[14] Hung \& Tzeng. (2007). Orthographic variation and visual information processing. Psychological Bulletin, 90.

[15] Harris, T.L. \& Hodges, R.E. (1995). The literacy dictionary: The vocabulary of reading and writing. Newark, DE: International Reading Association.

[16] Lipson, M, Y \& Wixson, K, K. (2003). Assessment and instruction of reading and writing disability: An interactive approach (3rd Ed). NY: Allyn \& Bacon.

[17] Miller, G. (1956). The magical number seven, plus or minus two: Some limits on our capacity for processing information. Psychological Review, 101, (2), 343-352. 1956.

[18] Malamed, Connie. (2012) Chunking Information for Instructional Design. Online. Retrieved at http://theelearningcoach.com/elearning_design/ chunking-information/.2015.

[19] Mai Huong (2020). Using Chunking technique in IELTS Reading for beginners. Published at https://zim.vn/ung-dung-ky-thuat-chunking-trongielts-reading-cho-nguoi-hoc-o-trinh-do-moi-bat-dau/. 
[20] Ommagio, iN. i(2006). iUnderstanding ireading. iNew iYork: iHolt iRinehart iand iWinston. ilnc.

[21] Johnson, D.D. \& Pearson, P.D. (1978). Teaching reading comprehension, New York: Holt, Rinehart \& Winston.

[22] Rivers, W. M. (1981). Teaching Foreign Language Skills (2nd edition). Chicago: University of Chicago Press

[23] Rasinski, T. V. (1989). Fluency for everyone. Incorporating fluency instruction in classroom. The Reading Teacher, 43, 690-693.

[24] Rini Anggraeni (2015). The effectiveness of using Chunking strategy to improve students' reading comprehension at the second year of SMP NEGERI 2 BAROMBONG. English Teaching Learning and Research Journal 2(2):299-312.

[25] Smith, A. P (1982). Handbook of human performance: Vol. 2. San Diego: Academic Press.

[26] Seyed iHossein iFazeli, iM. Iei(2010). iLanguage iin iIndia: iSome igaps iin ithe icurrent iStudies iof ireading iin iSecond/Foreign ilanguage ilearning. i(10)4,376-380).

[27] Snow, iCatherine. i(2002). iA icritical iconsumers' iguide ito ireading icomprehension iassessments ifor iadolescents. iNew iYork: iCarnegie iCorporation iof iNew iYork.

[28] Tanaka, S. (2006). Chunking method. In S. Tanaka, Y. Sato \& H. Abe (Eds.), Practical instruction giving learners an English awareness: Core and chunk usage (pp. 183-236), Tokyo: Taishukan Shoten.
[29] Thoa Vu (2020). What is Chunking? How do we use it? Published at https://timviec365.vn/blog/chunking-la-gi-new9561.html

[30] Wallace, C. (1992). Critical Literacy Awareness in the EFL Classroom. In N. Fairclough (Ed.), Critical Language Awareness (pp. 59-92). London: Longman.

[31] Wallace,C. (1992). Reading Oxford. Oxford University Press.

[32] Wiener, M. and W. Cromer. (1967). Reading and Reading Difficulty: A Conceptual Analysis. Harvard Educational Review, 37, No.4.

\section{AUTHORS}

First Author - Pham Thi Kieu Oanh, Foreign languages education faculty, Thai Nguyen University of Education Second Author - Dang Thi Thanh Dung, Foreign languages education faculty, Thai Nguyen University of Education Third Author - Ngo Thi Ngoc Anh, Foreign languages education faculty, Thai Nguyen University of Education 